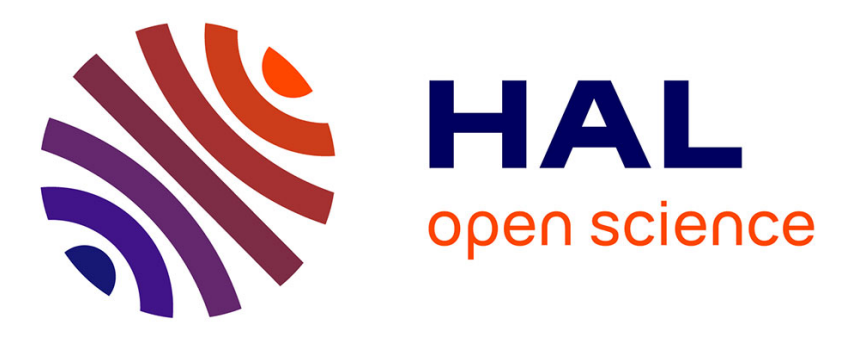

\title{
An experimental and computational analysis of a MOCVD process for the growth of Al films using DMEAA
}

Theodora C. Xenidou, Andreas. G. Boudouvis, Nicholas. C. Markatos, Diane Samélor, François Senocq, Nathalie Prud'Homme, Constantin Vahlas

\section{To cite this version:}

Theodora C. Xenidou, Andreas. G. Boudouvis, Nicholas. C. Markatos, Diane Samélor, François Senocq, et al.. An experimental and computational analysis of a MOCVD process for the growth of Al films using DMEAA. Surface and Coatings Technology, 2007, vol. 201, pp. 8868-8872. 10.1016/j.surfcoat.2007.04.080 . hal-00806220

\section{HAL Id: hal-00806220 https://hal.science/hal-00806220}

Submitted on 29 Mar 2013

HAL is a multi-disciplinary open access archive for the deposit and dissemination of scientific research documents, whether they are published or not. The documents may come from teaching and research institutions in France or abroad, or from public or private research centers.
L'archive ouverte pluridisciplinaire HAL, est destinée au dépôt et à la diffusion de documents scientifiques de niveau recherche, publiés ou non, émanant des établissements d'enseignement et de recherche français ou étrangers, des laboratoires publics ou privés. 


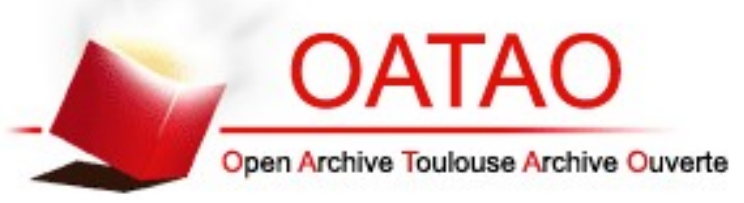

\section{Open Archive Toulouse Archive Ouverte (OATAO)}

OATAO is an open access repository that collects the work of Toulouse researchers and makes it freely available over the web where possible.

This is an author-deposited version published in: http://oatao.univ-toulouse.fr/ Eprints ID : 2447

To link to this article :

URL : http://dx.doi.org/10.1016/j.surfcoat.2007.04.080

To cite this version : Xenidou, T. C. and Boudouvis, A. G. and Markatos, N. C. and Samélor, D. and Senocq, François and Prud'Homme, N. and Vahlas, Constantin ( 2007) An experimental and computational analysis of a MOCVD process for the growth of Al films using DMEAA. Surface and Coatings Technology, vol. 201 ( $\mathrm{n}^{\circ} 22$ - 23). pp. 8868-8872. ISSN 0257-8972

Any correspondence concerning this service should be sent to the repository administrator:staff-oatao@inp-toulouse.fr 


\title{
An experimental and computational analysis of a MOCVD process for the growth of Al films using DMEAA
}

\author{
T.C. Xenidou ${ }^{a, *}$, A.G. Boudouvis ${ }^{\text {a }}$, N.C. Markatos ${ }^{\text {a }}$, D. Samélor ${ }^{b}$, F. Senocq ${ }^{\text {, }}$, \\ N. PrudHomme ${ }^{\text {b }, C . ~ V a h l a s ~}{ }^{b}$ \\ ${ }^{a}$ School of Chemical Engineering, National Technical University of Athens, 9 Heroon Polytechniou Str., Zographou Campus, GR-15780 Athens, Greece \\ ${ }^{\mathrm{b}}$ Centre Interuniversitaire de Recherche et d'Ingénierie des Matériaux, CIRIMAT-CNRS ENSIACET, 118 Route de Narbonne, 31077 Toulouse cedex 4 , France
}

\begin{abstract}
The analysis of a metal-organic chemical vapor deposition (MOCVD) process is performed by combining computational fluid dynamics (CFD) simulations and experimental measurements. The analysis is applied to a vertical, cold-wall reactor, where aluminum coatings are grown from dimethylethylamine alane (DMEAA), under low-pressure conditions. A two-dimensional model, based on the finite-volume method, is developed to predict the thermal and hydrodynamic characteristics of the flow within the MOCVD reactor, and the simulation results are compared with experimental data. It is shown that the computational predictions of the growth rates are in fair agreement with the experimental measurements.
\end{abstract}

Keywords: MOCVD process; Computational fluid dynamics; Aluminum; DMEAA

\section{Introduction}

Metal-organic chemical vapor deposition (MOCVD) is recently considered as an important technique for manufacturing high-quality coatings of various semi-conducting materials. Aluminum-based MOCVD has been widely used for highly conformal coverage of complex surfaces and good contact fill in the production of integrated circuits. Among the metal-organic precursors for Al MOCVD, dimethylethylamine alane (DMEAA) has been extensively used during the last decade, due to its attractive properties, such as the relatively high vapor pressure at room temperature and its liquid state [1,2]. In addition, DMEAA contains no direct Al-C bonds, thus ensuring the production of carbon-free aluminum films [3].

The successful implementation of a MOCVD process in the large-scale production of semi-conducting compounds depends on the ability to determine optimal operating conditions in a

\footnotetext{
* Corresponding author. Tel.: +30 210 7723235; fax: +30 2107723228 .

E-mail address: thexen@central.ntua.gr (T.C. Xenidou).
}

well-designed reactor configuration. Transport phenomena are very complex in MOCVD processes and to predict the film growth rate accurately, gas flow, heat transfer and chemical reactions have to be considered simultaneously. Numerical simulations based on computational fluid dynamics (CFD) have been used successfully in recent years to design new MOCVD reactors or to find the optimal operating conditions for existing designs [4-6]. However, few simulations have been reported for Al MOCVD from DMEAA [7].

Aiming, in the near future, at the manufacturing of metallurgical coatings composed of $\mathrm{Al}-\mathrm{Cu}$ complex metallic alloys, deposition experiments and CFD simulations were combined in this study in order to develop a predictive model for aluminum growth through DMEAA dissociation in sub-atmospheric pressure (about 10 Torr) and in the temperature range of 473-493 K. This temperature range was selected because it is compatible with MOCVD of $\mathrm{Cu}$ from $\mathrm{CpCuPEt}_{3}$ as shown in a companion paper in this volume [8]. The availability of a commercial CFD code to solve the coupled differential equations assisted the numerical analysis of the aluminum MOCVD process. This leads to a reduction of the number of experiments required and, therefore, of the total cost of the process optimization. 


\section{Experimental procedure}

Aluminum deposition was experimentally investigated in the cylindrical, low-pressure MOCVD reactor, illustrated in Fig. 1. The reactor is equipped with a showerhead above a 304Lstainless steel susceptor. The outer walls of the reactor are made of stainless steel 316L. The dimensions of the showerhead are $17 \mathrm{~mm}$ (height) $\times 62 \mathrm{~mm}$ (inner diameter). The shower plate $(0.5 \mathrm{~mm} \times 60 \mathrm{~mm})$ consists of 1450 holes of diameter of $0.38 \mathrm{~mm}$. Single-cystalline silicon substrates $(5 \mathrm{~mm} \times 10 \mathrm{~mm})$ were placed at specific positions on the susceptor.

Aluminum is deposited through the dissociation of adduct grade DMEAA $\left(\left[\left(\mathrm{CH}_{3}\right)_{2} \mathrm{C}_{2} \mathrm{H}_{5}\right] \mathrm{NAlH}_{3}\right)$ to DMEA $\left(\left[(\mathrm{CH} 3)_{2} \mathrm{C}_{2} \mathrm{H}_{5}\right] \mathrm{N}\right)$, alane $\left(\mathrm{AlH}_{3}\right)$ and hydrogen:

$$
\begin{aligned}
& {\left[\left(\mathrm{CH}_{3}\right)_{2} \mathrm{C}_{2} \mathrm{H}_{5}\right] \mathrm{NAlH}_{3}(\mathrm{~g}) \rightarrow \mathrm{Al}(\mathrm{s})+\left[\left(\mathrm{CH}_{3}\right)_{2} \mathrm{C}_{2} \mathrm{H}_{5}\right] \mathrm{N}(\mathrm{g})} \\
& \quad+3 / 2 \mathrm{H}_{2}(\mathrm{~g})
\end{aligned}
$$

DMEAA vapor was delivered to the reactor chamber using a bubbler, maintained at 281-282 K. Mass flow controllers delivered $99.999 \%$ pure nitrogen that was used as carrier gas and as dilution gas.

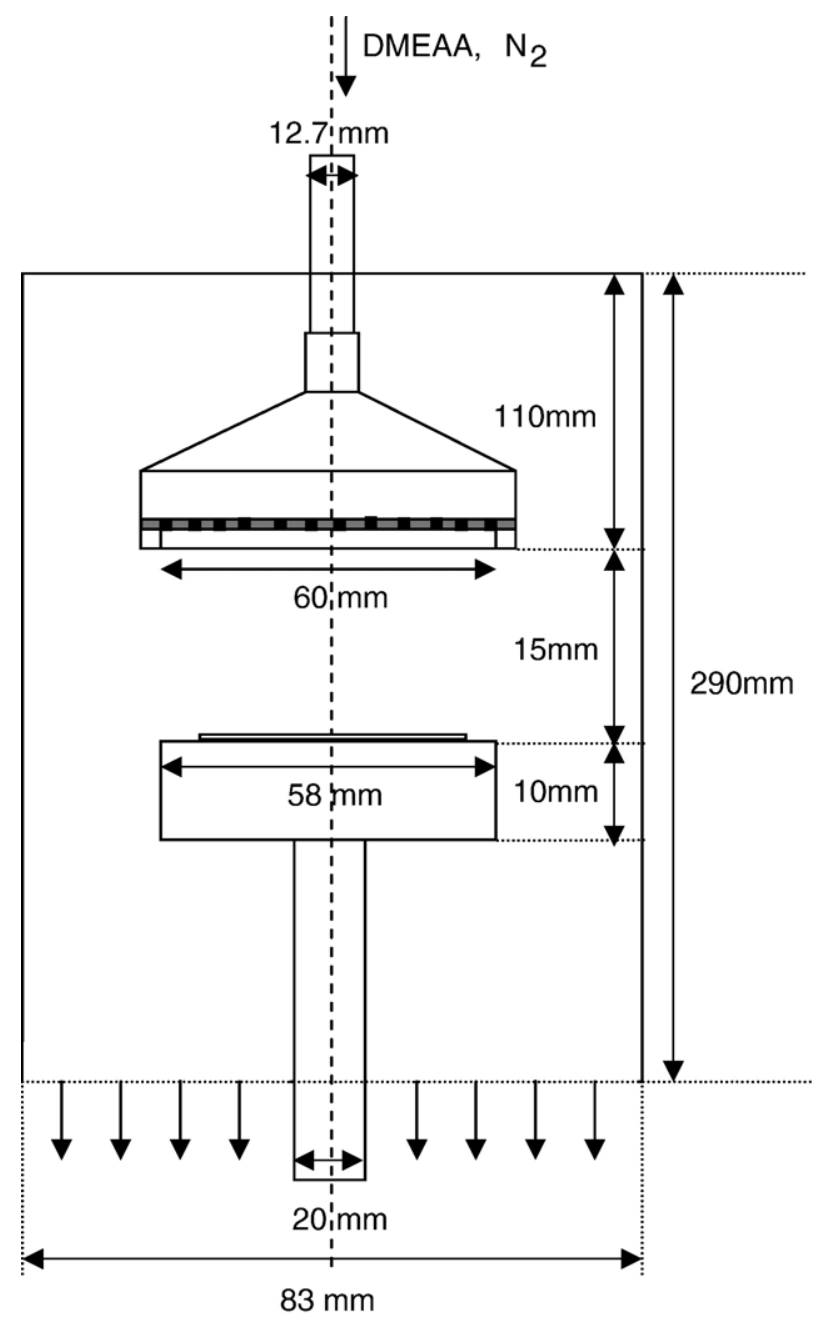

Fig. 1. Schematic view of the MOCVD reactor.
Table 1

Typical operating conditions for the simulation of Al MOCVD

\begin{tabular}{lll}
\hline Operating parameter & Symbol [unit] & Value \\
\hline $\mathrm{N}_{2}$ dilution flow rate & $F_{\mathrm{d}}(\mathrm{sccm})$ & 305 \\
$\mathrm{~N}_{2}$ carrier flow rate & $F_{\mathrm{c}}(\mathrm{sccm})$ & 25 \\
Bubbler temperature & $T_{\mathrm{b}}(\mathrm{K})$ & 282 \\
DMEAA flow rate & $F_{\mathrm{p}}(\mathrm{sccm})$ & 1,4 \\
Inlet gas temperature & $T_{\mathrm{in}}(\mathrm{K})$ & 338 \\
Substrate temperature & $T_{\text {react }}(\mathrm{K})$ & 473 \\
Walls temperature & $T_{\text {wall }}(\mathrm{K})$ & 298 \\
Total pressure & $P($ Torr $)$ & 10 \\
\hline
\end{tabular}

A mechanical pump, along with a pressure measurement device and a control system (MKS), was employed to maintain the total pressure in the reactor at 10 Torr during the deposition experiments. Heating is provided from the susceptor through a resistance coil gyred just below the surface. A K-type thermocouple connected to a controller and placed inside the susceptor was used for the temperature control of the silicon substrate. Temperature at inlet and reactor walls was also measured during the deposition experiments. Typical operating conditions are summarized in Table 1. Upon completion of the deposition step, the power was turned off so that the samples cooled down at room temperatures in a $\mathrm{N}_{2}$ gas stream. Deposition rate was measured at five positions over the substrate, through the weight gain of each sample.

\section{Mathematical model}

The phenomena involved in MOCVD processes include coupled fluid flow, heat transfer, mass transport of multiple gas species and chemical reactions in the gaseous phase and on the heated substrates. In this study, the coupled partial differential equations for the conservation of momentum, energy, total mass and individual species were used to develop a mathematical model of the Al deposition process. Some reasonable simplifying assumptions have been made to reduce the complexity of the numerical problem, as follows: the gases, being highly diluted in nitrogen, are considered to obey the ideal gas law and Newton's law of viscosity; the gaseous mixture is assumed to behave as a continuum under steady state conditions; heating due to viscous dissipation is neglected; pressure variations in the energy equation are neglected as the Mach number is very small. The gas flow is characterized by a low Reynolds number $\left(R e=V L / v_{\text {ref }}=17<100\right)$, thus ensuring the laminar flow assumption. $L$ is the characteristic dimension, selected as the radius of the vertical inflow pipe, $V$ is the characteristic velocity, selected as the inlet velocity, and $v_{\text {ref }}$ is the kinematic viscosity at the reference gas temperature $T_{\text {ref }}=\left(T_{\text {wafer }}+T_{\text {wall }}\right) / 2$. The effect of buoyancy driven convection is also included in the model. The relative importance of natural convection, due to temperature differences, and forced convection, owning to inlet flow, varies as the mixed convection parameter $G r / R e^{2}$. The Grashof number $G r=g R_{\mathrm{w}}^{3}\left(T_{\text {wafer }}-T_{\text {wall }}\right) /\left(v_{\text {ref }}^{2} T_{\text {ref }}\right)$, based on the wafer radius, is 33.3 , and the ratio $G r / R e^{2}$ is 0.115 . Hence, forced convection is dominant in this reactor under the operating conditions examined in the present study. 
Radiative heat transfer primarily occurs through the exchange of thermal energy between the susceptor and the solid parts of the reactor. Due to the low deposition temperatures $(473-493 \mathrm{~K})$ examined in the present study, the addition of radiation effects is not expected to be significant. Hence, heat transfer due to radiation is not accounted for in the simulations. Mass conservation accounts for multicomponent as well as thermal diffusion. All equations above can be cast in the following general form [9]:

$\nabla \cdot\left(\rho \vec{V} \varphi_{n}-\Gamma_{\varphi_{n}} \nabla \varphi_{n}\right)=S_{\varphi_{n}}$

In Eq. (2), $\rho$ is the density, $\vec{V}$ is the velocity vector, $\Gamma_{\varphi_{n}}$ is the effective exchange coefficient of variable $\varphi_{n}$ and $S_{\varphi_{n}}$ is the source/sink term expressing the production/consumption of $\varphi_{n}$ inside the domain of interest.

The boundary conditions were taken as follows:

- At the inlet, the velocity distribution is considered uniform; the gas feed is assumed to be at $338 \mathrm{~K}$; the species mass fractions are set at the experimental values.

- At the outlet, exiting gases are supposed to flow in an environment of specified operating pressure; zero normal derivatives are applied for all dependent variables (velocity, temperature and mass fractions).

- At the symmetry axis, zero normal derivatives are applied for all dependent variables.

- At any solid surfaces, the no-slip condition for gas velocity is applied.

- At the outer walls of the reactor, the temperature is fixed at $298 \mathrm{~K}$.

- At the shower plate, the pressure drop is specified; the porosity of the plate is defined.

While the simplification of uniform substrate surface temperature is commonly used in the numerical simulation of CVD processes (e.g., $[10,11]$ ), a conjugate heat transfer model between the heating susceptor below the substrate and the fluid above it is closer to the experimental setup. In the present model, this is achieved through coupling of the substrate surface temperature to the convective heat transfer of the inlet gas and the conductive heat transfer within the stainless steel susceptor. The temperature was fixed to the experimentally measured value inside the susceptor at a position of 3-4 $\mathrm{mm}$ from the substrate surface.

At the substrate surface, the flux of each chemical species, reactant or product, is determined by the diffusion rate to the substrate surface as explained below.

Previous experimental work of our group has shown that the kinetically-controlled regime extends between $403 \mathrm{~K}$ and $463 \mathrm{~K}$. Jang et al. [3] reported a transition temperature of $433 \mathrm{~K}$ for the $\mathrm{Al}$ growth with DMEAA source on $\mathrm{Si}, \mathrm{SiO}_{2}$ and TiN substrates. As mentioned in the Introduction, $\mathrm{Al}$ growth through DMEAA dissociation is investigated in the temperature range of 473$493 \mathrm{~K}$, where the growth takes place in the transport-controlled regime. The growth rate is described by the formula adopted by many researchers $[12,13]$ that combines gas-phase diffusion of reactants to the substrate surface and surface chemical reactions. In the transport-controlled regime surface reaction is very fast, thus chemical kinetics is not accounted for in the simulation, and the growth rate approaches the diffusive flux of the reactants to the substrate surface. The sticking coefficient of DMEAA on open adsorption sites is assumed to be 1.0. The rate of consumption of the reactant and the rate of production of the species, based on the growth rate according to the stochiometry of the overall surface reaction (Eq. (1)), are applied as boundary conditions to the diffusion equations.

The species included in the gas mixture are the ones appearing in the overall dissociation reaction (Eq. (1)). The absence of other gas-phase species is supported by previous studies [14-16]. Experimental results implied that DMEAA dissociates readily in DMEA and alane and the epitaxial growth of Al films arises from alane activity on the film surface $[14,15]$. The elementary surface reactions of alane and its dissociation products have been further investigated, employing density functional theory and a cluster model [16].

Detailed description of mixing rules used for the calculation of the properties of the N-component gas mixture can be found in Ref. [17]. The Lennard-Jones parameters of the different chemical species are taken from Ref. [7]. The MOCVD process model is implemented in PHOENICS, a commercial CFD code [18], which is based on the finite-volume method (FVM). Details on the solution procedure are given in Ref. [19]. The two-dimensional computational domain was spatially discetizated in curvilinear coordinates [20] in order to support the detailed description of the showerhead. The total number of finite volumes required to produce a grid-independent solution was equal to $33.075(105 \times 315(\mathrm{NX} \times \mathrm{NZ}))$ and typical $\mathrm{CPU}$ time for obtaining a converged solution of the coupled equations is about $120 \mathrm{~min}$ on a $2.8 \mathrm{GHz}$ Pentium 4/1.0 GB RAM.

\section{Results and discussion}

\subsection{Model predictions at typical conditions}

Fig. 2 shows the isotherms and velocity vectors, calculated at the typical operating conditions summarized in Table 1. As it is clearly shown, the temperature field is uniform above the substrate surface, which is a consequence of the fact that conduction is dominant compared to convection. In the upper left part of the reactor, the isotherms follow the shape of the showerhead, an implication of the heat transfer through the showerhead walls.

The temperatures at the shower plate were set at their experimentally measured values, for different substrate temperatures. It was observed that this practice did not affect the characteristics of the temperature distribution inside the reactor.

The velocity vectors in Fig. 2 illustrate a large recirculation zone in the showerhead. The presence of this relatively large zone may be attributed to the local pressure drop, due to the flow velocity increase and the change of the flow direction at the showerhead. This zone will trap the gas mixture components 


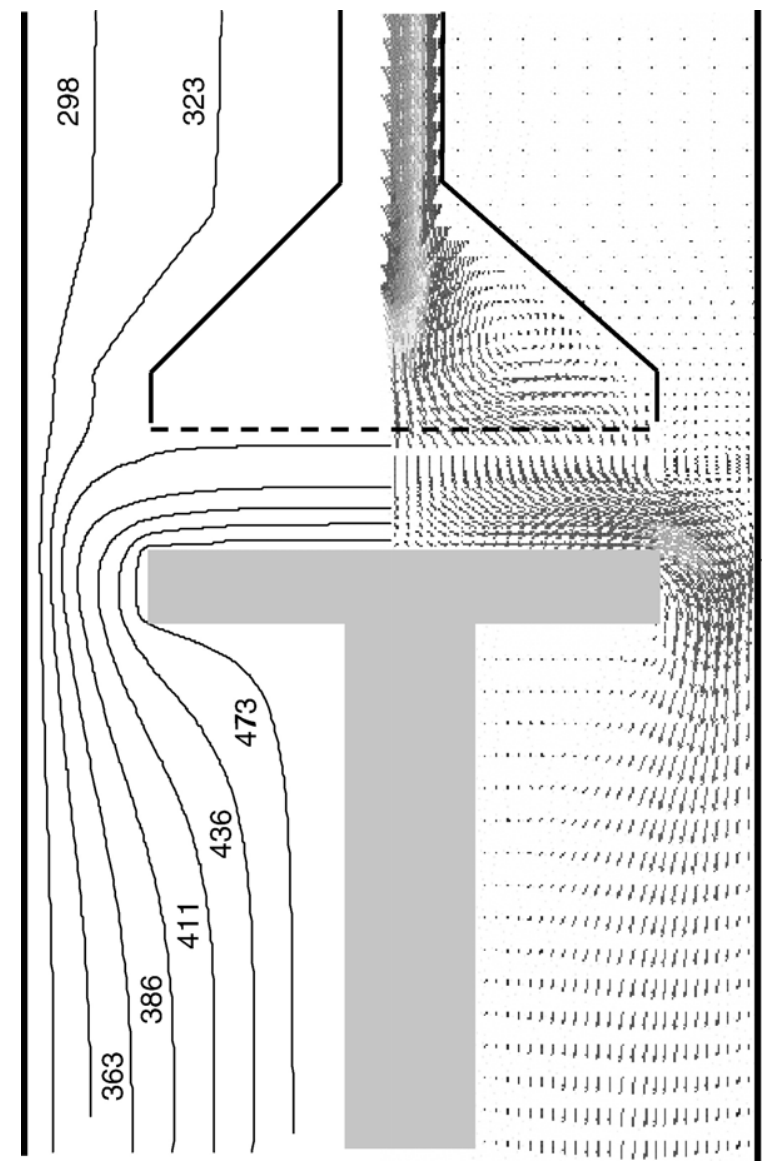

Fig. 2. (a) Temperature contours and (b) velocity vectors at typical operating conditions summarized in Table 1.

inside the showerhead and cause the precursor to condensate, a highly undesirable scenario. However, it may provide premixing of the gas mixture components, which is beneficial to the thickness uniformity of the film. A second recirculation zone appears under the substrate; this weak recirculation is mainly due to the expansion of the flow path.

The radial distribution of the normalized species mass fractions just above the substrate surface, at the typical operating conditions, is shown in Fig. 3. $\mathrm{N}_{2}$ concentration is particularly uniform in the radial direction, with an almost constant mass fraction of 0.98. DMEAA mass fraction remains constant at $1.55 \times 10^{-2}$ and it increases a little at the end of the substrate. As expected, an inverse trend is observed for the DMEA and $\mathrm{H}_{2}$, which are the main reaction products. Specifically, the DMEA mass fraction starts decreasing from $1.44 \times 10^{-3}$ to $1.03 \times 10^{-3}$ at $15 \mathrm{~mm}$ from the center of the substrate. Finally, the $\mathrm{H}_{2}$ mass fraction varies between $1.85 \times 10^{-5}$ and $1.39 \times 10^{-5}$, from $10 \mathrm{~mm}$ to $25 \mathrm{~mm}$ along the substrate. These results actually represent the formation of an aluminum thin layer on the substrate surface.

\subsection{Comparison of experiments and predictions}

The experimental measurements are compared with the model predictions, at $473 \mathrm{~K}$ and $493 \mathrm{~K}$, in Fig. $4 \mathrm{a}$ and b, respectively, while all other operating parameters correspond to

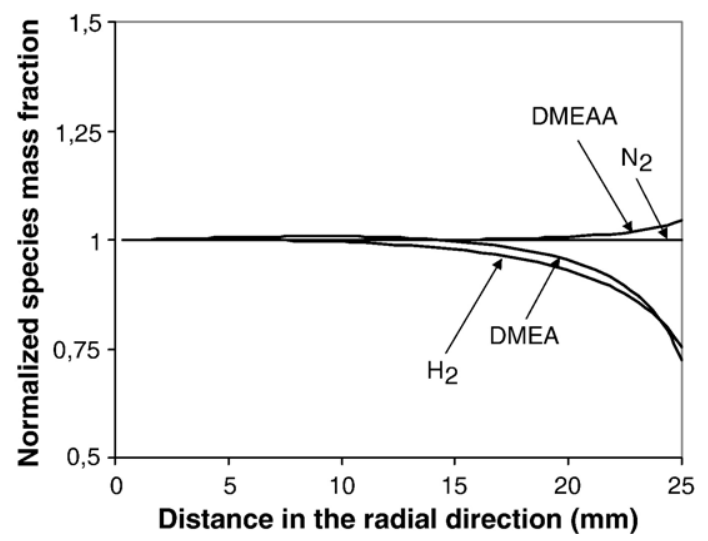

Fig. 3. Normalized species mass factions in the radial direction of the substrate, at the typical operating conditions summarized in Table 1.

the typical values summarized in Table 1 . The predicted growth rates are calculated as explained in the Mathematical model section without any parameter fitting. According to the experimental measurements, the growth rate increases in the radial direction at both temperatures. The results in Fig. 4a $(473 \mathrm{~K})$ indicate that the model predictions of the increase of aluminum growth rate in the radial direction are in fair

(a)

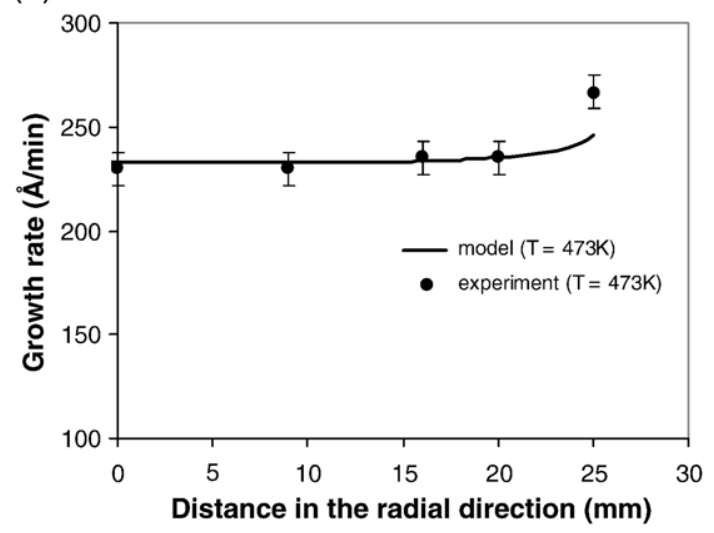

(b)

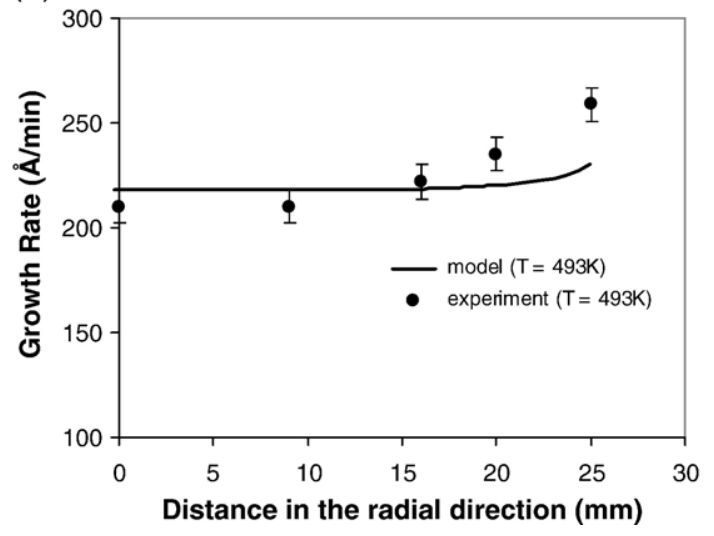

Fig. 4. Al growth rate on the substrate surface along the radial direction, at (a) $T_{\text {react }}=473 \mathrm{~K}$ and (b) $T_{\text {react }}=493 \mathrm{~K}$. Computations vs experimental measurements. 
agreement with the measurements. Taking into account that the experimental error for the growth rate is $\pm 8 \AA / \mathrm{min}$, the comparison in Fig. 4b (493 K) is satisfactory. Moreover, the experimental growth rate at $493 \mathrm{~K}$ is smaller and it seems to be less uniform compared to the growth rate at $473 \mathrm{~K}$. Note that the slight decrease of the experimentally observed growth rate with temperature has also been observed by the computations and is attributed to reduction of the diffusive flux due to thermal diffusion [21]. Specifically, the calculation of diffusive mass fluxes due to thermal diffusion is based on an exact formula, using binary thermal diffusion coefficients [22]. When temperature increases from $473 \mathrm{~K}$ to $493 \mathrm{~K}$, the binary thermal diffusion coefficient increases and the DMEAA mass fraction decreases from $1.55 \times 10^{-2}$ to $1.47 \times 10^{-2}$ at the center of the substrate and from $1.62 \times 10^{-2}$ to $1.54 \times 10^{-2}$ at the edge of the substrate, respectively. The lower DMEAA mass fractions at $493 \mathrm{~K}$ yield smaller growth rates.

\section{Concluding remarks}

This work provides a computational framework for the analysis of aluminum growth through dimethylethylamine alane dissociation under low-pressure conditions. A computational fluid dynamics model is developed to describe the complex transport phenomena involved in a vertical cold-wall MOCVD reactor. The model was found to predict, fairly well, the experimentally measured growth-rate profiles in the radial direction. It was found that increasing the temperature from $473 \mathrm{~K}$ to $493 \mathrm{~K}$, the growth rate decreases by approximately $5.7 \%$.

\section{Acknowledgements}

Financial support was provided by the General Secretariat for Research and Technology of Greece through the Programme for "Greece-France cooperation in Research and Technology" (2006-2008) and by the Agence Nationale de la Recherche in France through contract no. NT05-3_41834. This work was conducted in part in the frame of the EC network of excellence no. NMP3-CT-2005-500140. The authors are thankful to the reviewers for their useful comments and suggestions.

\section{References}

[1] J.-H. Yun, B.-Y. Kim, S.-W. Rhee, Thin Solid Films 312 (1998) 259.

[2] M. Delmas, D. Poquillon, Y. Kihn, C. Vahlas, Surf. Coat. Technol. 200 (2005) 1413.

[3] T.W. Jang, W. Moon, J.T. Baek, B.T. Ahn, Thin Solid Films 333 (1998) 137.

[4] C.E.C. Dam, A.P. Crzegorczyk, P.R. Hageman, R. Dorsman, C.R. Kleijn, P.K. Larsen, J. Cryst. Growth 271 (2004) 192.

[5] L. Kandinski, V. Merai, A. Palekh, H. Ramer, E.A. Armour, R. Stall, A. Gurary, A. Galyukov, Y. Marakov, J. Cryst. Growth 261 (2004) 175.

[6] S.M. Liu, S.L. Gu, S.M. Zhu, J.D. Ye, W. Liu, X. Zhou, R. Zhang, Y. Shi, Y.D. Zheng, J. Cryst. Growth 299 (2007) 303.

[7] W.-S. Choi, J.-M. Ahn, J.-H. Bae, S.-K. Suh, J.-H. Yun, S.-W. Rhee, Proc. 13th Int. Conf. on CVD, 96/5, The Electrochemical Society, Pennington, NJ, 1996, p. 131.

[8] F. Senocq, A. Turgambaeva, N. PrudHomme, U. Patil, V.V. Krisyuk, D. Samelor, A. Gleizes, C. Vahlas, this volume.

[9] S.V. Patankar, Numerical Heat Transfer and Fluid Flow, Taylor \& Francis, 1980.

[10] C.R. Kleijn, Thin Solid Films 365 (2000) 294.

[11] G. Luo, S.P. Vanka, N. Glumac, Int. J. Heat Mass Transfer 47 (2004) 4979.

[12] J.I. Ulacia, S. Howell, H. Korner, Ch. Werner, Appl. Surf. Sci. 38 (1989) 370.

[13] C.R. Kleijn, C.J. Hoongendoorn, A. Hasper, J. Holleman, J. Middelhoek, J. Electrochem. Soc. 138 (2) (1991) 509.

[14] Y. Neo, M. Niwano, H. Mimura, K. Yokoo, Appl. Surf. Sci. 142 (1999) 443.

[15] J.-H. Yun, M.-Y. Park, S.-W. Rhee, J. Vac. Sci. Technol. 16 (1998) 419.

[16] T. Nakajima, M. Nakatomi, K. Yamashita, Mol. Phys. 101 (1-2) (2003) 267.

[17] T.C. Xenidou, M.K. Koukou, A.G. Boudouvis, N.C. Markatos, J. Phys. IV 11 (2001) Pr3-183.

[18] CHAM Ltd. Phoenics code, Version 3.5.1, London, 2004.

[19] T.C. Xenidou, A.G. Boudouvis, D.M. Tsamakis, N.C. Markatos, J. Electrochem. Soc. 151 (12) (2004) C757.

[20] E.R. Galea, N.C. Markatos, Int. J. Heat Mass Transfer 34 (1991) 181.

[21] W.L. Holstein, J. Electrochem. Soc. 135 (7) (1988) 1788.

[22] C.R. Kleijn, Th.H. van der Meer, C.J. Hoogendoorn, J. Electrochem. Soc. 136 (11) (1989) 3423. 